\title{
Deciphering the role of anions and secondary coordination sphere in tuning anisotropy in Dy(III) air-stable $D_{5 h}$ SIMs
}

\author{
Sandeep K. Gupta, ${ }^{[a]}$ Sourav Dey, ${ }^{[a]}$ Thayalan Rajeshkumar, ${ }^{[a]}$ Gopalan Rajaraman ${ }^{\star[a]}$ and \\ Ramaswamy Murugavel ${ }^{*[a]}$
}

\begin{abstract}
Precise control of the crystal field and symmetry around the paramagnetic spin centre has recently facilitated the engineering of high-temperature single-ion magnets (SIMs), the smallest possible units for future spin-based devices. In the present work, we report a series of air-stable seven coordinate $\mathrm{Dy}(\mathrm{III})$ SIMs $\left\{\left[\mathrm{L}_{2} \mathrm{Dy}\left(\mathrm{H}_{2} \mathrm{O}\right)_{5}\right][\mathrm{X}]_{3} \cdot \mathrm{L}_{2} \cdot n\left(\mathrm{H}_{2} \mathrm{O}\right), n=0, \mathrm{X}=\mathrm{Cl}(\mathbf{1}), n=1, \mathrm{X}=\mathrm{Br}(\mathbf{2}), \mathrm{I}(\mathbf{3})\right\}$ possessing pseudo- $D_{5 \mathrm{~h}}$ symmetry or pentagonal bipyramidal coordination geometry with high anisotropy energy barrier $\left(U_{\text {eff }}\right)$ and blocking temperature $\left(T_{\mathrm{B}}\right)$. While the strong axial coordination from the sterically encumbered phosphonamide, ${ }^{\mathrm{B}} \mathrm{BuPO}\left(\mathrm{NH}^{\mathrm{P} P r}\right)_{2}$ (L), increases the overall anisotropy of the system, the presence of high symmetry significantly quenches quantum tunnelling of magnetization, which is the prominent deactivating factor encountered in SIMs. Although the local coordination geometry and the symmetry around the Dy(III) in all the three complexes are similar and display only slight deviations, the variation of halide anions in the secondary coordination sphere which is hydrogen-bonded to the coordinated equatorial water molecules, show subtle alteration in the magnetic properties. The energy barrier $\left(U_{\text {eff }}\right)$ and the blocking temperature $\left(T_{\mathrm{B}}\right)$ decrease in the order $\mathbf{3}>\mathbf{2}>\mathbf{1}$ with the change of anions from larger iodide to smaller strongly hydrogen-bonded chloride in the secondary coordination sphere. Ab initio CASSCF/RASSI-SO/SINGLE_ANISO calculations further provide deeper insights into the dynamics of magnetic relaxation in addition to the role of the secondary coordination sphere in modulating the anisotropy of the $D_{5 \mathrm{~h}}$ systems, using diverse models. Thus, in addition to the importance of the crystal field and the symmetry to obtain high-temperature SIMs, this study also probes the significance of the secondary coordination sphere that can be tailored to accomplish novel SIMs.
\end{abstract}

\section{Introduction}

Single-molecule magnets (SMMs) are superparamagnetic molecules that behave as molecular-level classical magnets at low temperatures. ${ }^{[1]}$ This scripts them as potential candidates for fabrication of next-generation high-density data storage devices. ${ }^{[2]}$ Besides, they are also recognized as prospective candidates for application in future molecular spintronics and

[a] Dr. S. K. Gupta, Mr. Sourav Dey, Dr. T. Rajeshkumar, Prof. G. Rajaraman and Prof. R. Murugavel

Department of Chemistry

Indian Institute of Technology Bombay

Powai, Mumbai, India-400 076

E-mail:rmv@chem.iitb.ac.in

Supporting information for this article is given via a link at the end of the document. quantum computing due to the observance of phenomena such as quantum tunneling of magnetization (QTM) and quantum phase interference. ${ }^{[3]}$ However, these properties are witnessed only at very low temperatures in most SMMs, thus rendering them unfit for technological applications. While the first slow relaxation of magnetization in a molecular complex was observed in a ' $\mathrm{Mn}_{12}$ ' cluster, ${ }^{[4]}$ the report on high energy barrier $\left(U_{\text {eff }}\right)$ in the double-decker complexes, $\left[\mathrm{PC}_{2} \mathrm{~Tb}\right][\mathrm{TBA}]^{+}$, by Ishikawa et al. in 2003 shifted the attention to lanthanide ions for designing SMMs with high $U_{\text {eff. }}{ }^{[5]}$

In the last decade, several groups have made remarkable efforts to decrypt the factors that can aid the synthesis of SMMs with higher blocking energy barriers $\left(U_{\text {eff }}\right)$ and blocking temperatures $\left(T_{\mathrm{B}}\right)$. Particularly lanthanide ions having electronic configurations greater than $4 \mathrm{f}^{7}$ such as $\mathrm{Dy}(\mathrm{III}), \mathrm{Er}(\mathrm{III})$, and $\mathrm{Tb}$ (III) are more attractive due to large spin-orbit (SO) coupling and larger magnetic moments (as the f-orbitals are deeply buried and shielded, they do not significantly interact with the crystal field (CF)). ${ }^{[1 d, 6]}$ However, the presence of significant QTM in the case of $4 \mathrm{f}$ complexes between the ground state doublets significantly inhibits the slow relaxation of magnetization. QTM has been quenched by either incorporating a radical that induces a strong exchange coupling or a $3 \mathrm{~d}$ metal ion in the complex. ${ }^{[7]}$ QTM has also been quenched either by maintaining a strong axiality and/or a higher-order symmetry. ${ }^{[1 \mathrm{~d}, 6 \mathrm{c}, 6 \mathrm{f}, 8]}$ In 2011, Reinhart and Long put forward an idea based on the electrostatic model that proposed that a specific CF could be designed to enhance the anisotropic charge distribution of $4 \mathrm{f}$ ions. ${ }^{[6]}$ While strong axial coordination makes oblate ions such as $\mathrm{Dy}(\mathrm{III}), \mathrm{Tb}(\mathrm{III})$, etc., more anisotropic, the reverse is true for ions with prolate electronic charge distribution. Thus, a better understanding of the elements that play a decisive role in realizing the slow relaxation dynamics such as the effect of crystal field (CF) and the symmetry in addition to the synthetic efforts, has resulted in SMMs with $U_{\text {eff }}$ and $T_{\mathrm{B}}$ values as high as $1541 \mathrm{~cm}^{-1}$ and $80 \mathrm{~K}$, respectively in a dysprosocenium complex. ${ }^{[8 d]}$ While maintaining a strict axial symmetry seems to readily impart a very high anisotropic barrier in Ln(III) SIMs as recently reported in some interesting $D_{4 \mathrm{~h}}, D_{5 \mathrm{~h}}, D_{6 \mathrm{~h}}$ symmetric systems, the nature of axial ligand and geometry around the central $\operatorname{Ln}(\mathrm{III})$ ion seems to be very important to obtain higher blocking temperatures. ${ }^{[6 \mathrm{~d}, 6 \mathrm{f}, 8 \mathrm{a}, 9]}$ While $D_{4 \mathrm{~h}}$ and $D_{6 \mathrm{~h}}$ systems appear to impart very high $U_{\text {eff, }}$ they suffer from significant QTM at zero-field as observed in the magnetic hysteresis loop measurements. ${ }^{\left[{ }^{9 d-f]}\right.}$ Thus, the high $U_{\text {eff }}$ does not always translated in high $T_{\mathrm{B}}$. Moreover, apart from possessing high $U_{\text {eff }}$ and $T_{\mathrm{B}}$, these molecules also need to retain additional properties such as stability, solution processability and sublimability for fabrication. Therefore, it becomes necessary to outline design strategies to synthesize air stable SIMs/SMMs. 
In the present work, we report a series of air-stable pseudo$D_{5 \mathrm{~h}}$ symmetric Dy(III) SIMs, $\left\{\left[\mathrm{L}_{2} \mathrm{Dy}\left(\mathrm{H}_{2} \mathrm{O}\right)_{5}\right][\mathrm{X}]_{3} \cdot \mathrm{L}_{2} \cdot n\left(\mathrm{H}_{2} \mathrm{O}\right), n=0, \mathrm{X}\right.$ $=\mathrm{Cl}(\mathbf{1}), n=1, \mathrm{X}=\mathrm{Br}(2), \mathrm{I}(3)\}$, that exhibit high anisotropy energy barrier $\left(U_{\text {eff }}\right)$ and blocking temperature $\left(T_{\mathrm{B}}\right)$. These SIMs have been rationally designed from a sterically encumbered phosphonamide ${ }^{t} \mathrm{BuPO}(\mathrm{NH} / \mathrm{Pr})_{2}$. This study particularly unravels the role of halide ions in the secondary coordination sphere in fine-tuning the magnetic properties. The effect of coordinated halide anions on the SIM properties of $3 d$ and $4 f$ ions has been recently reported. ${ }^{[10]}$ The magnetic properties of complex 3 has been reported by our group in a previous communication. ${ }^{[6 f]}$ These SIMs possesses some of the highest $U_{\text {eff }}$ and $T_{\mathrm{B}}$ values for any air-stable $3 \mathrm{~d}$ or $4 \mathrm{f}$ systems. Additional $a b$ initio calculations performed disclose the role of the phosphonamide ligand, secondary coordination sphere, and the higher-order symmetry in the realization of unique properties exhibited by these complexes.

\section{Results and Discussion}

\section{Synthetic aspects and molecular structures}

The sterically bulky phosphonic diamide, [ $\mathrm{B}$ BPO $\left.\left(\mathrm{NH}^{i} \mathrm{Pr}\right)_{2}\right](\mathrm{L})$, was derived from the reaction of tert-butylphosphonic dichloride, ${ }^{t} \mathrm{BuPOCl}_{2}$, and excess isopropyl amine employing a literature procedure. ${ }^{[11]}$ The pentagonal-bipyramidal dysprosium complexes, $\left\{\left[\mathrm{L}_{2} \mathrm{Dy}\left(\mathrm{H}_{2} \mathrm{O}\right)_{5}\right][\mathrm{X}]_{3} \cdot \mathrm{L}_{2} \cdot n\left(\mathrm{H}_{2} \mathrm{O}\right), n=0, \mathrm{X}=\mathrm{Cl}(\mathbf{1}), n=1\right.$,

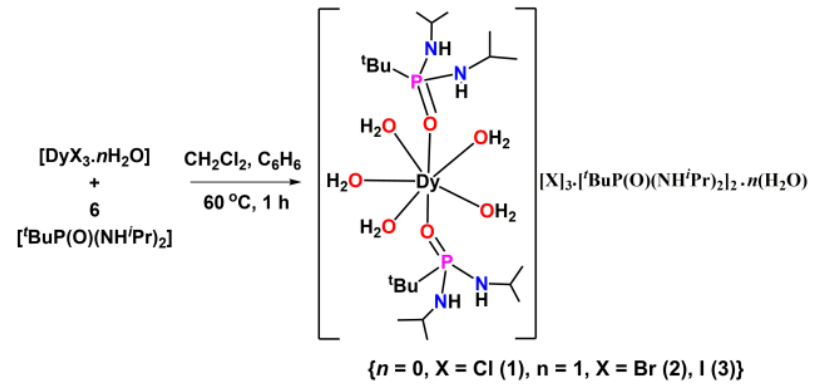

Scheme 1. Synthesis of the seven coordinate Dy(III) complexes of the phosphonic diamide ligand.

$X=\operatorname{Br}(\mathbf{2}), I(3)\}$, were synthesized from the direct reaction of the corresponding lanthanide halide hydrates with six equivalents of the ligand (Scheme 1). The compounds were obtained as crystals at ambient aerobic conditions via the slow evaporation of the reaction mixture. The structurally analogous $Y(I I I)$ complexes were synthesized using similar synthetic protocol $\left\{\left[\mathrm{L}_{2} \mathrm{Y}\left(\mathrm{H}_{2} \mathrm{O}\right)_{5}\right][\mathrm{Cl}]_{3} \cdot \mathrm{L}_{2} \cdot \mathrm{CH}_{2} \mathrm{Cl}_{2}(\mathbf{4}),\left[\mathrm{L}_{2} \mathrm{Y}\left(\mathrm{H}_{2} \mathrm{O}\right)_{5}\right][\mathrm{X}]_{3} \cdot \mathrm{L}_{2} \cdot \mathrm{H}_{2} \mathrm{O}, \mathrm{X}=\mathrm{Br}(\mathbf{5})\right.$, $\mathrm{I}(6)\}$. Crystals obtained from the mother liquor were separated and characterized by both analytical and spectroscopic techniques. All the complexes display a broad IR band around $3300 \mathrm{~cm}^{-1}$ corresponding to the $\mathrm{N}-\mathrm{H}$ stretching vibrations (Figure S1). Two strong characteristic $\mathrm{P}=\mathrm{O}$ bands were observed at a)

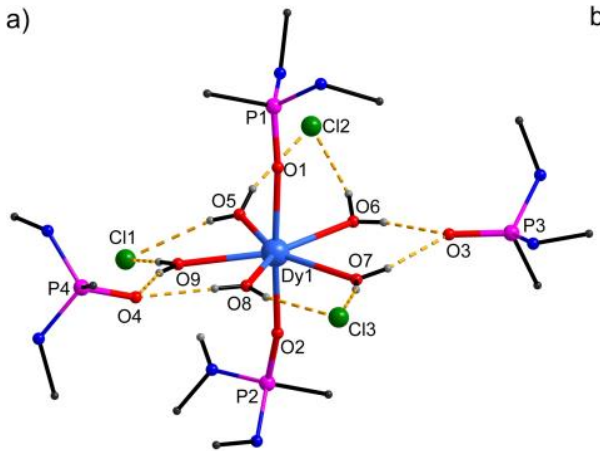

b)

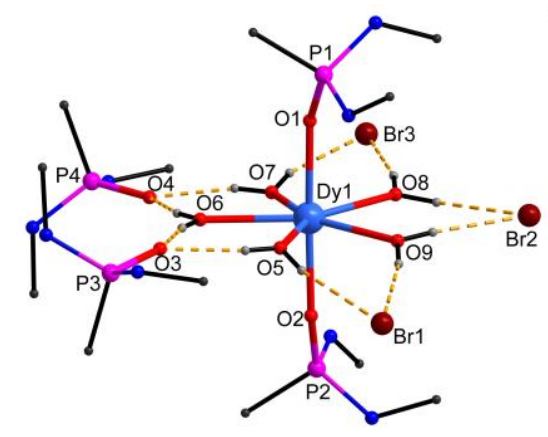

c)

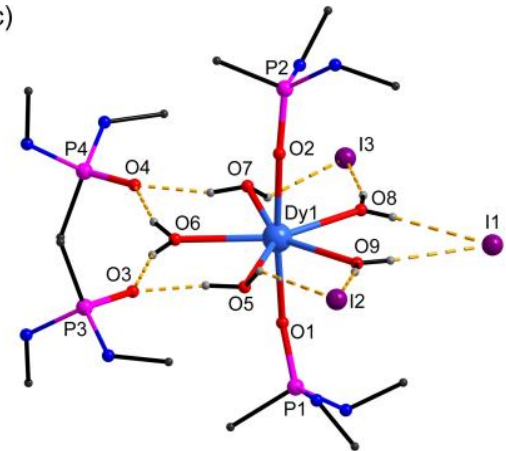

Figure 1. Molecular structures of the pseudo- $D_{5 \mathrm{~h}}$ dysprosium(III) complexes 1-3 (a-c). Lattice water molecule and $\mathrm{H}$-atoms attached to carbon centres have been omitted for clarity. The $\mathrm{H}$-atoms of the water molecules are hydrogen bonded to the halide anions and lattice phosphonic diamide ligands forming a starlike architecture. Dashed yellow bonds indicate H-bonding.

a)

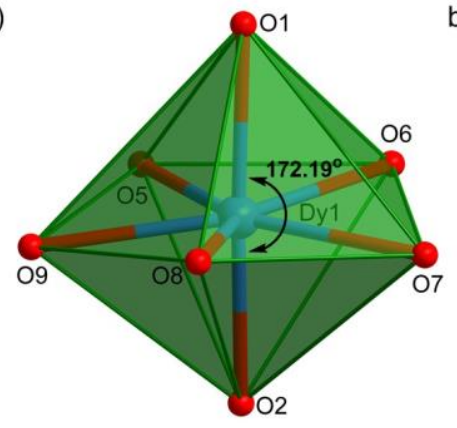

Average Dy-O(P) $=2.2077 \mathrm{~A}$ b)

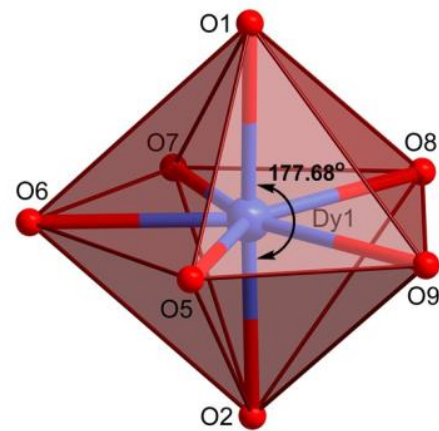

Average Dy-O(P) $=2.2125 \mathrm{~A}$ c)

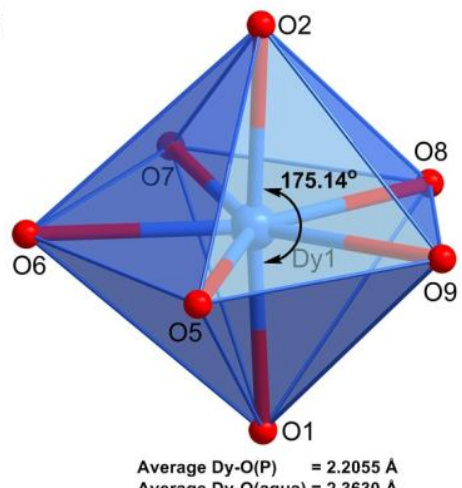

Figure 2. Comparative polyhedral view of the pentagonal bipyramidal coordination environment of $D y(I I I)$ ion in $1-3(\mathrm{a}-\mathrm{C})$ with ligating oxygen atoms. 
around $1100 \mathrm{~cm}^{-1}$ for all the complexes due to the presence of two types of $\mathrm{P}=\mathrm{O}$ bonds, one in the lattice and the other coordinated to the metal ion.

Single crystal X-ray diffraction analyses reveal that all the three complexes have a similar core structure around the central Dy(III) ion, whilst some differences are found in the arrangement of the anions and the neutral lattice ligands in the secondary coordination sphere. Complex $1,\left[\mathrm{~L}_{2} \mathrm{Dy}\left(\mathrm{H}_{2} \mathrm{O}\right)_{5}\right][\mathrm{Cl}]_{3} \cdot \mathrm{L}_{2}$, crystallizes in the orthorhombic space group Pbca. The asymmetric part of the unit cell contains one seven coordinate dysprosium ion coordinated to two phosphonic amide ligands and five water molecules (Figure 1). In addition, there are two phosphonic amide ligands present in the lattice along with three chloride anions, which balance the overall charge. The coordination sites in the equatorial plane of the dysprosium ion are occupied by the water molecules and the axial sites are coordinated by the phosphoryl oxygen atom of the amide ligand. Analysis of the $\left\{\mathrm{DyO}_{7}\right\}$ core ion using SHAPE 2.1 ${ }^{[12]}$ shows the least deviation (0.492) from the $D_{5 \mathrm{~h}}$ symmetry suggesting that Dy(III) ion occupies a distorted pentagonal bipyramidal coordination environment (Figure 2 and Table S2). The axial Dy-O(P) distances (2.203(1) and 2.213(1) $\AA$ ) are shorter than the equatorial Dy-O(aqua) distances (2.335(2) 2.407(2) $\AA$ ). This, in addition to the near-linear trans $O(P)-D y-O(P)$ angle $\left(172.19(6)^{\circ}\right)$, renders a virtual quasi-two coordinate coordination environment to the Dy(III) ion, a highly sought after geometry in the case of $4 \mathrm{f}-\mathrm{SMMs}{ }^{[13]}$ The two Dy-O-P angles are $169.53(1)^{\circ}$ and $166.89(1)^{\circ}$. The hydrogen atoms of the water molecules coordinated to the Dy(III) ion are hydrogen-bonded to three chloride anions and two neutral phosphonic diamide ligands giving a star-like $\mathrm{H}$-bonded architecture (Figure 1). The closest

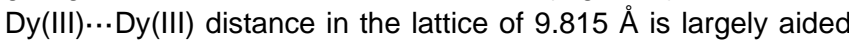
by the presence of two uncoordinated phosphonic diamide ligands and the three chloride ions present in the lattice per formula unit. The chloride ions are further involved in weak $\mathrm{H}$ bonding with the amide protons giving rise to a two-dimensional network of mononuclear dysprosium complexes (Figure S2).
Complexes 2 and 3 crystallize in the triclinic space group $P \overline{1}$ and are isomorphous. While the primary coordination sphere around the Dy(III) ion in $\mathbf{2}$ and $\mathbf{3}$ have similar core structural features as in complex 1 (Figure 1, 2, and Table 1), they differ in the arrangement of the non-coordinated three lattice anions and two phosphonic amide ligands in the second coordination sphere. Besides, one molecule of water is present in the lattice. The trans $\mathrm{O}(\mathrm{P})$-Dy-O $(\mathrm{P})$ angle is more linear in $2\left(177.68(8)^{\circ}\right)$ and 3 $\left(175.14(9)^{\circ}\right)$ compared to 1 . However, the major difference appears in the bent P-O-Dy angle, where the bent angle is more linear in the case of $\mathbf{1}$. This also leads to the decrease of the distance of phosphorous atom from the mean $\left\{\mathrm{DyO}_{5}\right\}$ equatorial plane in $\mathbf{2}$ and $\mathbf{3}$ as compared to $\mathbf{1}$. With increasing anion size, the average Dy(III) $\cdots \mathrm{X}$ and $\mathrm{X} \cdots \mathrm{O}$ (aqua) distances increase $(\mathrm{X}=$ halide). This also results in a considerable increase of nearest Dy(III) - .Dy(III) distance in the crystal lattices of 2 (10.459 $\AA$ ) and $3(10.819 \AA)$. Further, the increase in the ionic size of the lattice anions leads to the weakening of $\mathrm{X} \cdots \mathrm{H}-\mathrm{O}$ hydrogen bonds in 2 and 3 (see supporting information). Analysis of the $\left\{\mathrm{DyO}_{7}\right\}$ core with the standard symmetry using SHAPE $2.1^{[12]}$ suggests an almost ideal $D_{5 \mathrm{~h}}$ symmetry with a deviation of 0.18 and 0.223 for 2 and 3, respectively (Table S2). The corresponding diamagnetic Y(III) complexes 4-6 also reveal similar core structural features. While complex 4 crystallizes in the monoclinic space group $P 2_{1} / \mathrm{c}$, complexes $\mathbf{5}$ and $\mathbf{6}$ crystallize in the triclinic space group $P \overline{1}$ as in the case of their dysprosium analogues.

\section{Magnetic Studies}

The static and dynamic magnetic susceptibility measurements of 1-3 have been carried out using an MPMS-XL SQUID magnetometer. The direct current (dc) susceptibility measurements carried out on a polycrystalline sample under an applied magnetic field of 1000 Oe shows $\chi_{\mathrm{M}} \mathrm{T}$ values of 14.09 13.90 , and $14.15 \mathrm{~cm}^{3} \mathrm{~K} \mathrm{~mol}^{-1}$ at $300 \mathrm{~K}$ for $1-3$, respectively, which is close to the estimated value of $14.18 \mathrm{~cm}^{3} \mathrm{~K} \mathrm{~mol}^{-1}$ for an isolated Dy (III) ion (ground state $={ }^{6} H_{15 / 2}$ ) (Figure S9). The $\chi_{\mathrm{M} T}$ values of

Table 1. Comparative bond lengths, bond angles and other structural parameters in 1-3

\begin{tabular}{|l|l|l|l|}
\hline Complex & \multicolumn{1}{|c|}{$\mathbf{1}$} & \multicolumn{1}{|c|}{$\mathbf{2}$} & \multicolumn{1}{|c|}{3} \\
\hline Trans O-Dy-O angle $\left(^{\circ}\right)$ & $172.19(6)$ & $177.68(8)$ & $175.14(9)$ \\
\hline Dy-O(P) distance $(\AA)$ & $2.2029(1), 2.2125(1)$ & $2.218(2), 2.207(2)$ & $2.208(2), 2.203(2)$ \\
\hline Dy-O(aqua) distance $(\AA)$ & $2.3353(2)-2.4071(2)$ & $2.343(2)-2.374(2)$ & $2.355(3)-2.375(3)$ \\
\hline Average Dy-O(aqua) distance $(\AA)$ & 2.363 & 2.358 & 2.363 \\
\hline P-O-Dy angle $\left(^{\circ}\right)$ & $169.53(1), 166.89(1)$ & $149.29(1), 156.35(1)$ & $149.72(1), 155.17(2)$ \\
\hline Equatorial O-Dy-O angles $\left(^{\circ}\right)$ & $69.91(7)-73.63(7)$ & $69.94(8)-73.47(8)$ & $70.43(9)-73.52(1)$ \\
\hline Sum of equatorial O-Dy-O angles $\left(^{\circ}\right)$ & 361.15 & 360.3 & 360.31 \\
\hline Average equatorial O-Dy-O angles $\left(^{\circ}\right)$ & 72.23 & 72.06 & 72.062 \\
\hline Nearest Dy-Dy distance in the lattice $(\AA)$ & 9.82 & 10.46 & 10.82 \\
\hline Average Dy-X distance $(\AA)$ & 4.556 & 4.803 & 5.038 \\
\hline Average nearest X-O(aqua) distance $(\AA)$ & 3.073 & 3.23075 & 3.446 \\
\hline
\end{tabular}


1-3 remain almost constant with lowering of the temperature, but fall sharply near $10 \mathrm{~K}$ indicating a large energy separation among the low-lying Kramers doublets (KDs), indicating magnetic blocking. The field $(H)$ dependent magnetization $(M)$ curve for 1 3 shows a sinusoidal behavior (Figure S10), a signature of large anisotropy, with a steep increase in magnetization at the lower field before reaching $\sim 5.0 \mu_{\mathrm{B}}$ at $7.0 \mathrm{~T}$ as seen in several hightemperature SMMs. ${ }^{[6]]}$

Alternating current (ac) susceptibility measurements were carried out to unravel the slow relaxation dynamics of 1-3 at zero applied dc field between 0.1 and $1500 \mathrm{~Hz}$ at an oscillating ac field of $3.5 \mathrm{Oe}$. Clear frequency and temperature-dependent maxima in the out-of-phase signals were observed up to $36 \sim 40 \mathrm{~K}$ for 1-3 indicative of a very high thermal energy barrier. Maxima in the outof-phase component of the frequency-dependent ac susceptibility $\left(\chi_{\mathrm{m}}\right)$ ) signals were observed up to $36 \mathrm{~K}$ for 1 indicative of a very high thermal energy barrier (Figure 3 ). To extract the relaxation times, the ac susceptibilities were fitted with a generalized Debye model which shows a temperature-dependent regime at higher temperatures. A linear fit of the temperature-dependent relaxation times $(\tau)$ at high temperatures to the Arrhenius law yields $U_{\text {eff }}=$ $582 \mathrm{~K}$ and $\tau_{0}=1.43 \times 10^{-11}$. However, complex 1 shows a linear behavior only until $30 \mathrm{~K}$ and deviates from linearity at lower temperatures indicating the presence of other competing relaxation processes. Thus the relaxation times extracted over the entire temperature range were treated considering the QTM, direct, Raman, and Orbach processes with the following expression: ${ }^{[14]}$

$$
\tau^{-1}=\tau_{Q T M}{ }^{-1}+A T+C T^{n}+\tau_{0}^{-1} \exp \left(-\frac{U_{e f f}}{k_{B} T}\right)
$$

a)

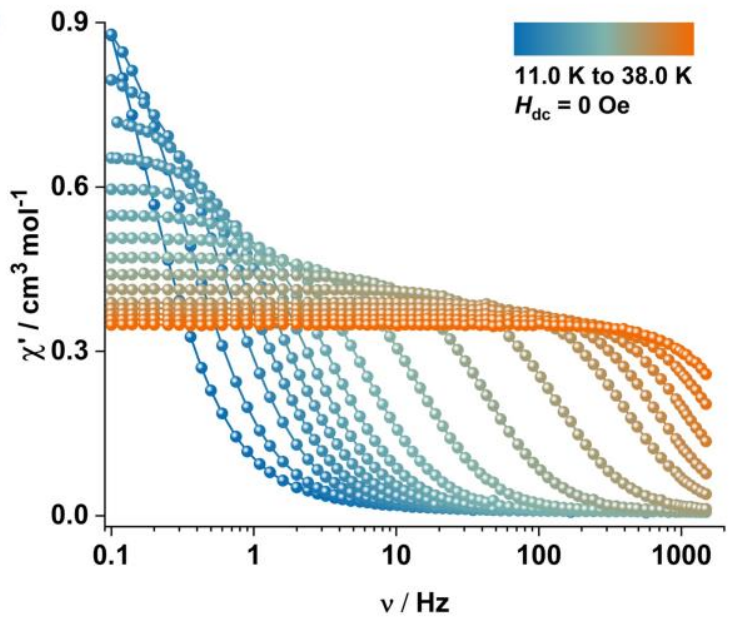

c)

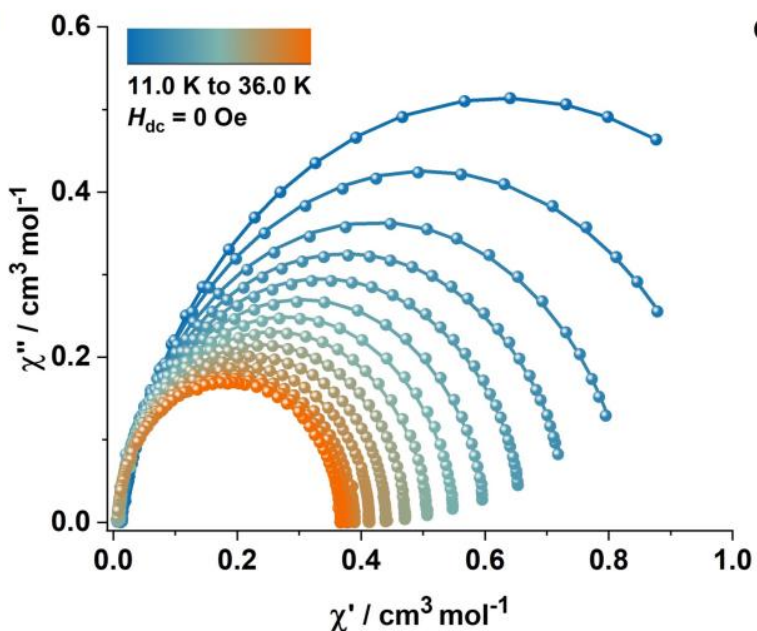

b)

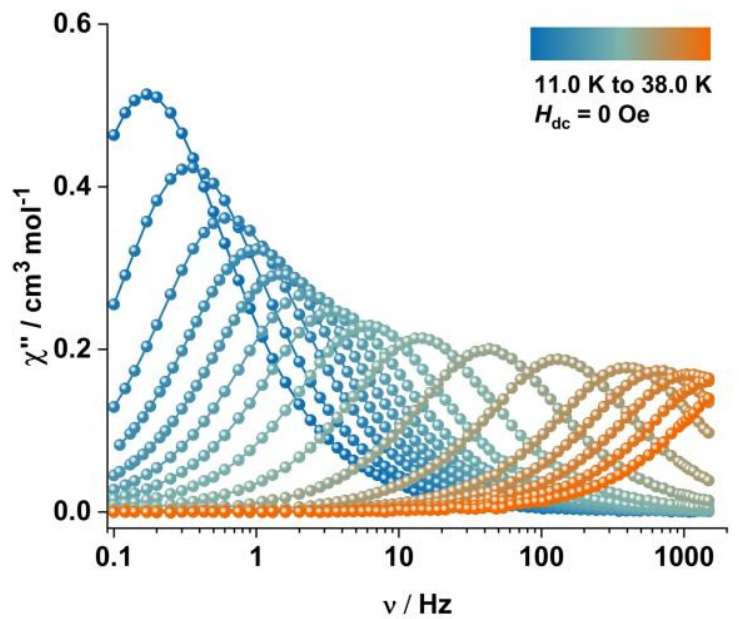

d)

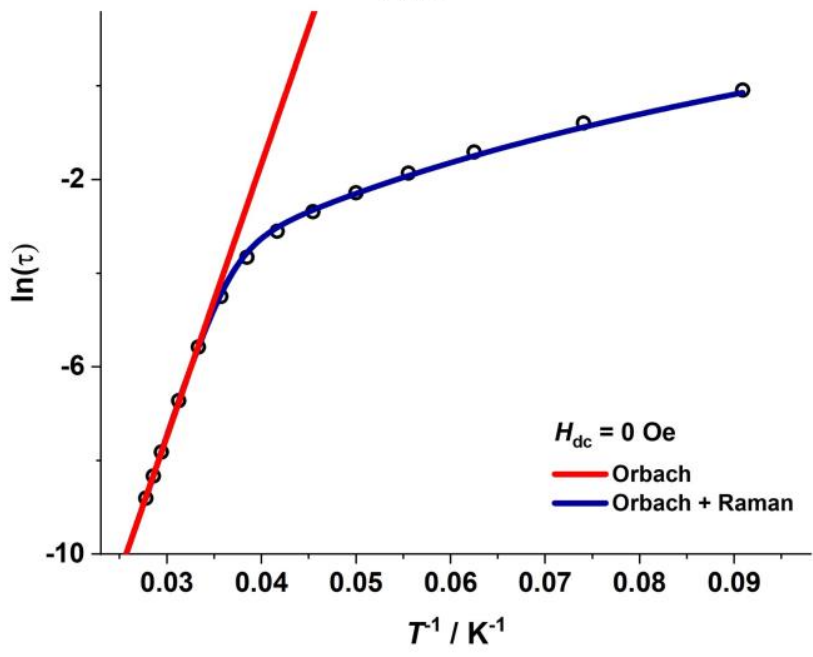

Figure 3. (a) In-phase $\left(\chi_{M}{ }^{c}\right)$ and (b) out-of-phase $\left(\chi_{M}{ }^{\prime \prime}\right)$ components of frequency dependent ac susceptibility measured in an oscillating ac field of 3.5 Oe and zero applied dc field for 1. (c) Cole-Cole plot for 1 . Solid lines are the best fit to the Debye model. (d) Plot of the relaxation time $\tau$ (logarithmic scale) versus $\mathrm{T}^{-1}$ obtained for 1 ; the red line corresponds to the fitting of the Orbach relaxation process and the solid blue line represents the best fitting to the Orbach and Raman relaxation pathways. 
a)

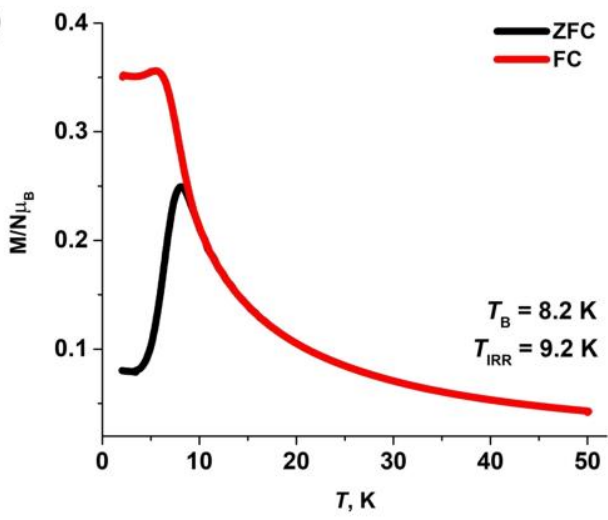

c)

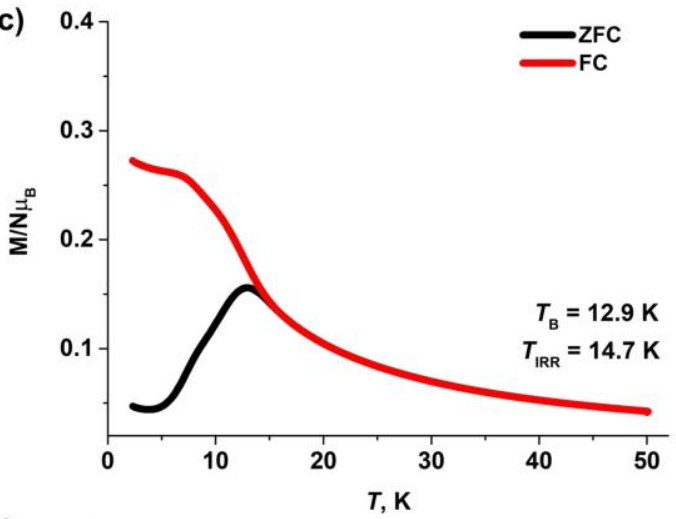

e)

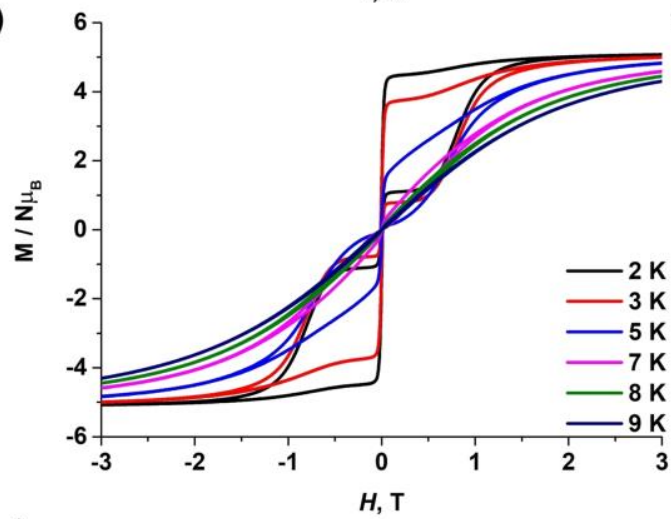

g)

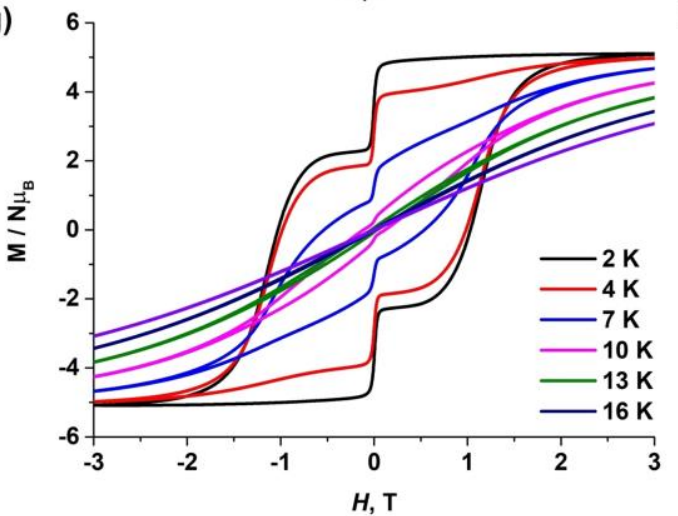

b) $\left.{ }^{0.4}\right] \quad$ ZFC

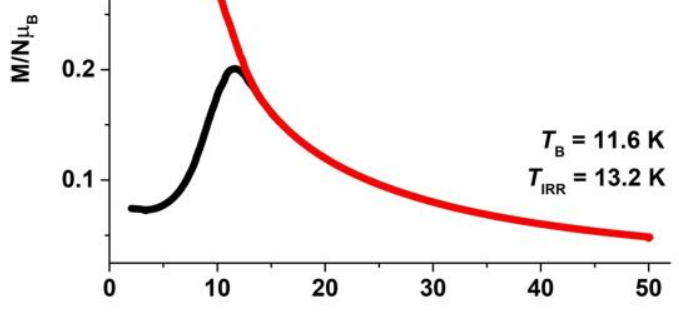

$T, \mathrm{~K}$

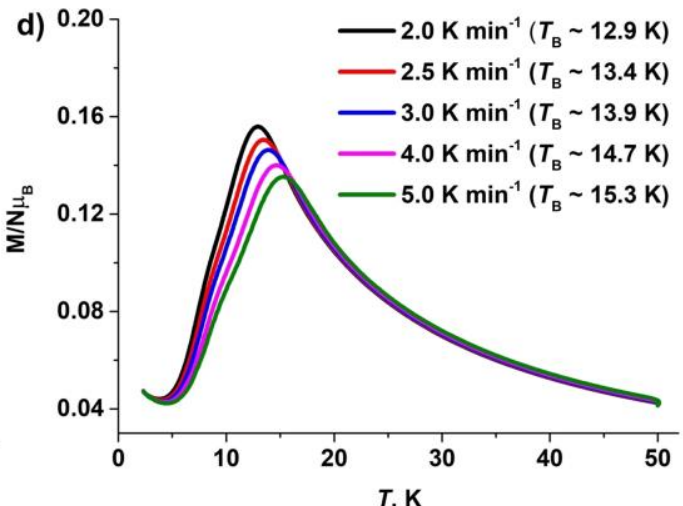

f)
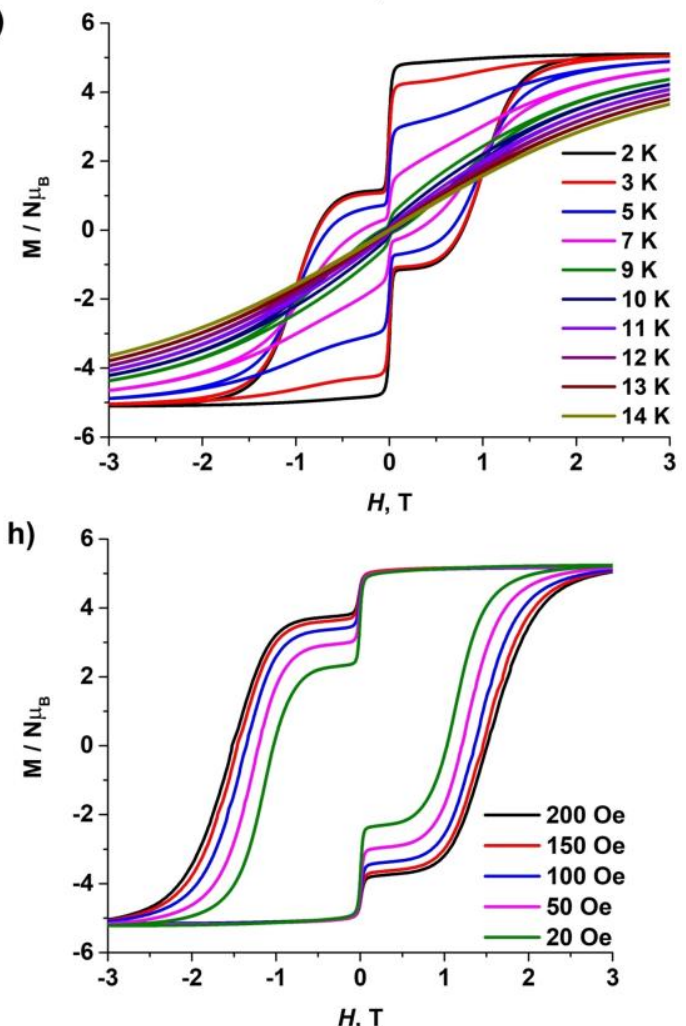

Figure 4. (a-c) Plot of zero field-cooled (black) and field-cooled (red) magnetization vs. temperature for 1-3. (d) Zero field-cooled magnetization $v s$. temperature for 3 at different temperature sweep rate. (e-g) The field-dependent magnetization data for 1-3 collected at a sweep rate of 20 $\mathrm{Oe} \mathrm{s}^{-1}$. (h) Comparative field-dependent magnetization data for 3 at a sweep rate of $20 \mathrm{Oe} \mathrm{s}^{-1}-200 \mathrm{Oe} \mathrm{s}^{-1}$. 
The best fit to eq. (1) for 1 yields an anisotropy barrier $U_{\text {eff }}$ of $609 \mathrm{~K}$ with $\tau_{0}=6.6 \times 10^{-12} \mathrm{~s}$, relative to the Orbach process with further contribution from the Raman relaxation mechanism ( $\left.C=2.04 \times 10^{-4} \mathrm{~s}^{-1} \mathrm{~K}^{-n}, n=3.6\right)$. This indicates that the QTM is effectively quenched due to the high symmetry around the Dy(III) ion and strong axial CF. The application of dc fields shows only a slight effect on the energy barrier (Figure S11). Complex 2 also displays similar relaxation dynamics like complex 1, nevertheless, the maxima in the out-of-phase are shifted towards higher temperature $(\sim 39.0 \mathrm{~K})$ while deviating from linearity below $30 \mathrm{~K}$ (Figure S15). The best fit to eq. (1) for 2 yields an anisotropy barrier $U_{\text {eff }}$ of $640 \mathrm{~K}$ with $\tau_{0}=1.06 \times 10^{-11} \mathrm{~s}$, relative to Orbach process with further contribution from the Raman relaxation pathway $\left(C=7.24 \times 10^{-7} \mathrm{~s}^{-1} \mathrm{~K}^{-\mathrm{n}}, \mathrm{n}=4.74\right)$ as observed in the case of complex 1. As in the previous case, the application of dc fields has only negligible effects on the energy barrier (Figure S16). A detailed comparative magnetic study of complex $\mathbf{3}$ along with the isomorphous $\mathrm{Er}$ (III) complex has been reported already in a previous communication. ${ }^{[6]}$ Thus, among the series, $U_{\text {eff }}$ decreases in the order $\mathbf{3}>\mathbf{2}>\mathbf{1}$ with the change of anions from larger iodide to smaller chloride in the secondary coordination sphere. These results are interesting as we find that although the local coordination environment in 1-3 is same, the replacement of halide anions in the secondary coordination sphere results in higher $U_{\text {eff }}$ in the order $\mathbf{3}>\mathbf{2}>\mathbf{1}$. This points out that the presence of higher negative charges in the equatorial position of oblate Ln(III) such as Dy(III) are detrimental to the effective $U_{\text {eff. }}$

To further ascertain the effect of halide ions on the SIM properties of these Dy(III) complexes, additional magnetic measurements were carried out. For example, zero-field cooled (ZFC) - field cooled (FC) variable temperature magnetization measurements were carried out to determine the blocking temperature of 1-3 (Figure $4 \mathrm{a}-\mathrm{d}$ ). $T_{\mathrm{B}}$ is defined as the maxima in the ZFC curve. ${ }^{[1 \mathrm{a}]}$ As can be seen from Figure 4, 3 possess the highest blocking temperature among the series. While $T_{\mathrm{B}}$ for 3 is $12.9 \mathrm{~K}$ (measured at a sweep rate of $2 \mathrm{~K} \mathrm{~min}^{-1}$ ), 2 and 1 possess $T_{\mathrm{B}}$ of $11.6 \mathrm{~K}$ and $8.2 \mathrm{~K}$, respectively. It is to be noted that the maxima in ZFC curves are highly dependent on the sweep rate (Figure $4 \mathrm{~d}$ ). $T_{\text {irr }}$ for 1, 2, and $\mathbf{3}$ are $14.7 \mathrm{~K}, 13.2 \mathrm{~K}$, and $9.2 \mathrm{~K}$, respectively. To further compare the magnetic blocking in 1-3, magnetic hysteresis measurements were carried out. Similar to the effect of sweep rate for ZFC-FC experiments, the opening of the hysteresis loop and coercivity are highly dependent on the magnetic field sweep rate (Figure $4 \mathrm{~h}$ ). Among the series, 1 possesses significant tunneling around zero-field as against 2 and 3. Further, the coercivity in the case of $\mathbf{1}$ is the least. $\mathbf{1}, \mathbf{2}$, and $\mathbf{3}$ display the opening of the hysteresis loop until $16.0 \mathrm{~K}, 14.0 \mathrm{~K}, 9.0$ $\mathrm{K}$, respectively (at a field sweep rate of $20 \mathrm{Oe} \mathrm{s}^{-1}$ ). A comparative summary of the magnetic data is presented in Figure 5 . These combined properties place these SIMs amongst the best performing SIMs that are stable to air and moisture. To further understand the relaxation dynamics, we prepared a $10 \%$ diluted sample (2@Y and 3@Y) with the isomorphous Y(III) analogues. However, 2@Y and 3@Y display similar magnetic properties as 2 and $\mathbf{3}$, thanks to the bulky phosphonic diamide ligands that keep the magnetic centers far apart in the crystal lattice. No significant improvement in blocking temperature and hysteresis were observed for 2@Y and 3@Y (Figures S23-S28).

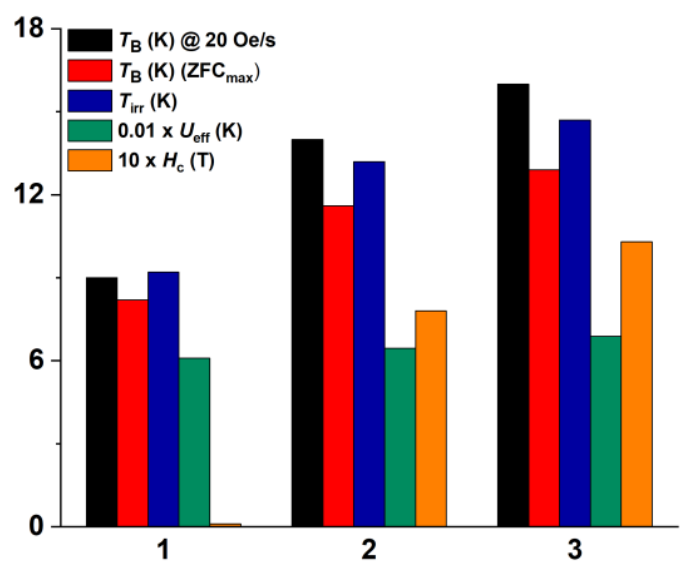

Figure 5. Comparative chart of the magnetic properties of SIMs 1-3.

\section{Electronic structure calculations}

To comprehend the effect of counter anion on the magnetic properties, we have performed ab initio CASSCF/RASSISO/SINGLE_ANISO calculations on complexes 1, 2, and 3 using MOLCAS 8.2 programme package ${ }^{[15]}$ (see computational details). The chosen $a b$ initio methodology was found to provide better guidance to obtain insights and understand the single-ion magnetism shown by lanthanide complexes. ${ }^{[9 \mathrm{~d}, 16]}$ The magnetic anisotropy axis of 1-3 is found to lie along the axial O-Dy-O bond, perpendicular to the ground state beta electron density [16a, 16b, 17] to minimize the electrostatic repulsions (Figure 6 and S30-32). The calculations reveal an axial set of $g$ tensors in the ground KD $\left(g_{\mathrm{x}}=g_{\mathrm{y}} \sim 0.0 ; g_{\mathrm{z}}=19.857\right.$ (1), 19.878 (2), 19.863 (3), Table S1214) and first excited KD. This enables negligible QTM/TA-QTM (TA = thermally activated) in the mechanism of magnetization relaxation (Figure 7). Furthermore, the angle of the anisotropy axis between ground and first excited states is found to be $<6^{\circ}$. This indicates magnetization relaxation via other higher excited states (Table S12-14). The eight ground KDs generated from the ${ }^{6} H_{15 / 2}$ state for the three complexes span up to 902.0 (1), 957.7 (2), and $1028.4 \mathrm{~K}(3)$. The significant TA-QTM value at the second excited state reinforces the magnetization relaxation $(|-15 / 2>\rightarrow|-$ $13 / 2>\rightarrow|-1 / 2>\rightarrow|+1 / 2>\rightarrow|+13 / 2>\rightarrow| 15 / 2>$, Figure 7). This results in large $U_{\text {cal }}$ values of $606.3,645.7$, and $668.9 \mathrm{~K}$ for $\mathbf{1}, \mathbf{2}$, and $\mathbf{3}$, respectively, consistent with the estimated $U_{\text {eff }}$ values (Table $S 12$ 14, Figure 7). 


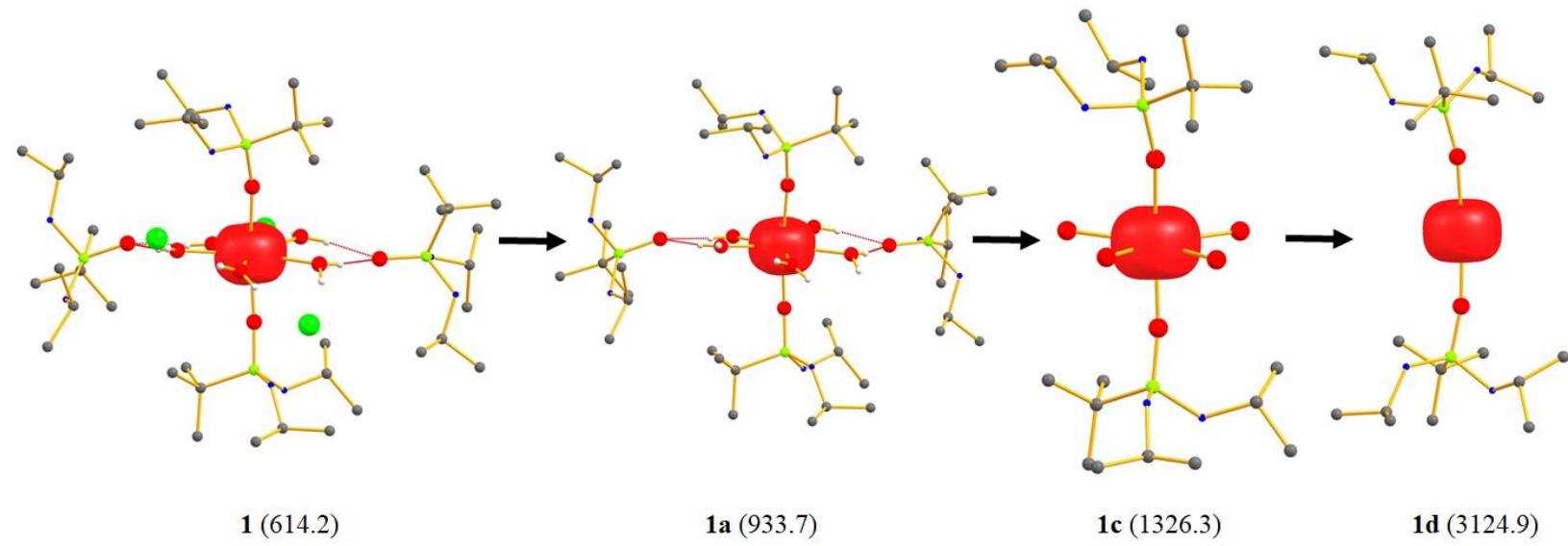

Figure 6. The $\beta$-electron density of $m_{J}=\mid \pm 15 / 2>$ from $\mathbf{1} \rightarrow \mathbf{1 a} \rightarrow \mathbf{1 b} \rightarrow \mathbf{1} \mathbf{c}$. The number in parenthesis indicates the $U_{\text {cal }}(\mathrm{K})$ value from ab initio CASSCF/RASSI-SO/SINGLE_ANISO calculations. Colour code: Cl-green, P-light green, O-red, N-blue, C-grey, H-white. Hydrogens (except equatorial hydrogens to show the hydrogen bonding) are omitted for clarity.

To find out the origin of the increasing $U_{\text {cal }}$ from $\mathbf{1} \rightarrow \mathbf{2} \rightarrow \mathbf{3}$, we have estimated the crystal field parameters using the Hamiltonian $\widehat{H}_{C F}=\sum_{k=2,4,6} \sum_{q=-k}^{q=+k} B_{k}^{q} \hat{O}_{k}^{q}$, (here $B_{k}^{q}$ is the crystal field parameter and $\hat{O}_{k}^{q}$ is the Stevens operator respectively). The value of larger axial crystal field $(\mathrm{CF})$ parameter $(\mathrm{k}=2,4,6 ; \mathrm{q}=0)$ compared to non-axial $(k=2,4,6 ; q \neq 0)$ suggests substantial axiality in all the three complexes (Table $S 15)$. The higher $U_{\text {cal }}$ value of 3 compared to 1 and 2 correlates with the larger axial $B_{2}^{0} \mathrm{CF}$ parameter. We have also estimated the $\frac{E_{2}-E_{1}}{E_{1}}\left(E_{2}\right.$ and $E_{1}$ is the spin free energy of the first and second excited state, respectively) which is considered as a figure of merit of axiality ${ }^{[17]}$ in Dy(III) SIM. The larger $\frac{E_{2}-E_{1}}{E_{1}}$ value of $\mathbf{2}$ and $\mathbf{3}$ compared to $\mathbf{1}$ suggests a larger axiality of the former compared to the latter (Table S16). The computed Loprop charges also explain the increasing axiality from $\mathbf{1} \rightarrow \mathbf{2} \rightarrow \mathbf{3}$. The Loprop charges on the equatorial water oxygens vary as $\mathbf{1}<\mathbf{2}<3$, but the charge of the surrounding halide counter anions decreases in the order $\mathbf{1}>\mathbf{2}>\mathbf{3}$ with a more pronounced effect, rationalizing the trend in the $U_{\text {cal }} / U_{\text {eff }}$ values (Table S17). To unravel whether the larger distance between Dy and iodide ions (av. Dy-halide distance is 5.04, 4.80 and $4.56 \AA$ in 3, 2 and 1, respectively) offers a larger $U_{\text {cal }}$ value in $\mathbf{3}$, we have performed a model calculation on $\mathbf{3}-\mathbf{C l}$ where the three iodide ions in 3 have been replaced by chloride ions. The calculation on $3-\mathbf{C l}$ reveals enhancement of $U_{\text {cal }}$ value to $693.4 \mathrm{~K}$ (Table S18) compared to 3, although a significant increase in the Loprop charges of chloride ions is observed (Table S17). This unveils the metal-halide distance rather than the nature of the halide ions controlling the magnetic anisotropy. On the other hand, in our earlier studies, we have established a structural $R$ parameter $\left.\left(R=\frac{\angle(O(P)-D y-O(P))}{1000}+A v \cdot[(D y-O e q)]-A v \cdot[D y-O a x)\right]\right) \quad$ to correlate it with the estimated $U_{\text {cal }}$ values in pseudo- $D_{5 \mathrm{~h}} \mathrm{Dy}$ (III) complexes. ${ }^{[16 a]}$ The $R$ value is found to be in the order of $\mathbf{3}>\mathbf{2} \mathbf{1}$, which also explains the trend in the $U_{\text {cal }}$ values (Table $S 19$ ).

Further, to analyze the effect of counter anions in magnetic anisotropy, we have removed the halide ions from the secondary coordination sphere of $\mathbf{1}, \mathbf{2}$, and $\mathbf{3}$ (model $\mathbf{1 a}, \mathbf{2} \mathbf{a}$, and $\mathbf{3} \mathbf{a}$, respectively, see Figure 5 and S30-31). Calculation on these models yields enhancement in $U_{\text {cal }}$ value to $1032.1,1115.5$, and $1079.5 \mathrm{~K}$ for $\mathbf{1 a}, \mathbf{2 a}$, and $\mathbf{3 a}$, respectively (Table S20-22). This is due to a reduction in the computed charge for the equatorial oxygen atoms (Table S23-25), compared to the original structure. Quite interestingly, the computed charge of the axial oxygen atoms increases in $\mathbf{1 a}, \mathbf{2 a}$, and $\mathbf{3 a}$ compared to $\mathbf{1}, \mathbf{2}$, and $\mathbf{3}$ (Table S23-25). Both these effects lead to the increase in the axial $B_{2}^{0} \mathrm{CF}$
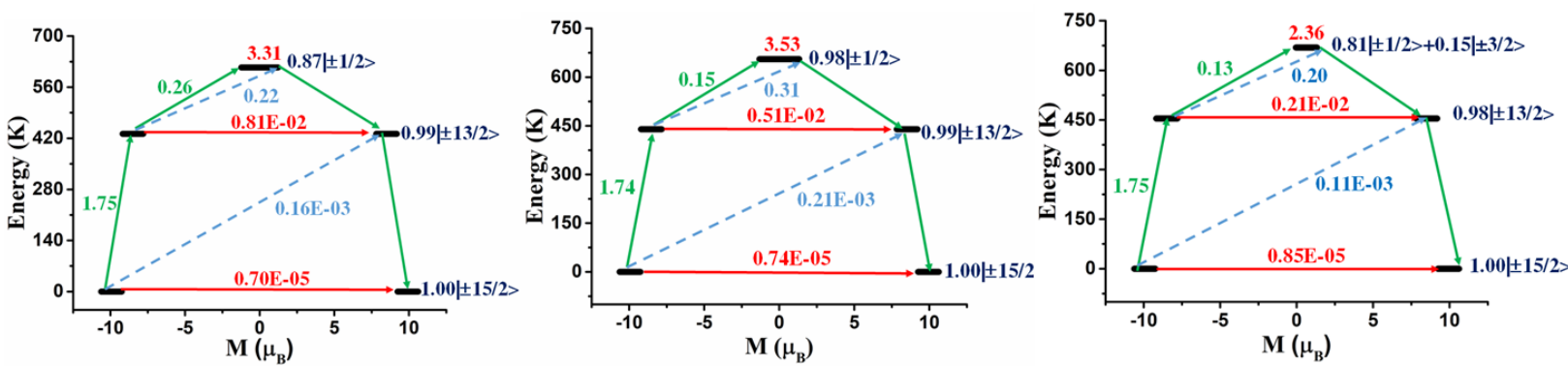

Figure 7. The mechanism of magnetic relaxation of $\mathbf{1}$ (left), $\mathbf{2}$ (middle), and $\mathbf{3}$ (right). The thick black line indicates the Kramer's doublet (KD) as a function of magnetic moment. The red arrow indicates QTM/TA-QTM via ground/excited states. The blue arrow indicates possible Orbach pathway. The green arrow indicates the most probable pathway of magnetic relaxation. The numbers associated with each arrow signifies the mean absolute values of corresponding matrix element of transition magnetic moment. The blue numbers indicate the ms composition of a KD. 
parameter (Table S26). For models, the $m_{J}=\mid \pm 11 / 2>$ stabilized as the second excited state, contrary to $\mathbf{1 , 2}$, and $\mathbf{3}$ (Table S2022) where $m_{J}=\mid \pm 1 / 2>$ was stabilized as second excited state, leading to magnetization relaxation via $3^{\text {rd }}$ excited state (Table S20-22).

To investigate the effect of non-coordinating phosphonamide ligands and halide ions in $U_{\text {cal }}$ value, the ligands have been removed from 1,2 , and 3 , keeping the halide ions intact (model 1b, 2b, and $\mathbf{3 b}$, respectively, see Figure S32 for beta electron density). The calculations yield a decrease in the $U_{\text {cal }}$ value $\left(U_{\text {cal }}=793.9(\mathbf{1 b}), 850.5(\mathbf{2 b})\right.$ and $\left.898.4 \mathrm{~K}(\mathbf{3 b})\right)$ compared to $\mathbf{1 a}, \mathbf{2} \mathbf{a}$ and $\mathbf{3 a}$ (the magnetization relaxation via second excited state, Table S27-29). In these models, equatorial oxygens were found to possess less charge as their hydrogen bonding solvates/halides were removed, placing their $U_{\text {cal }}$ values larger than 1, 2, and $\mathbf{3}$ (Table S23-25). More pronounced changes in the axial/equatorial oxygen charges and the computed crystal field parameters are observed in models $\mathbf{1 a} \mathbf{a} \mathbf{3} \mathbf{a}$ compared to $\mathbf{1 b} \mathbf{b} \mathbf{3 b}$ (Table S23-25, S30). This suggests that the halide counter anions (equatorial non-bonding interaction with Dy(III)) play a dominant role in magnetic anisotropy compared to the phosphonamide ligands (H-bonding interaction with equatorial water molecules)

In the next step, we have performed calculations on models 1c-3c where both halides and phosphonamide ligands were removed (see Figure 5 and S30-31). The ab initio calculations on these models reveal magnetization relaxation via third excited KD with the in the $U_{\text {cal }}$ value to 1343.7 (1c), 1407.2 (2c), $1403.1 \mathrm{~K}$ (3c) (see Table S31-33) with respect to the original structures and other models constructed. Here the computed values are twice as large as compared to the original structure (2.22 times in 1, 2.18 times in 2, 2.09 times in 3), and this can be rationalized from the computed charges and crystal field parameters (Table S23-25, S34). The $U_{\text {cal }}$ value of $\mathbf{2 c}$ is slightly higher compared to $\mathbf{3 c}$ due to the larger $\mathrm{O}(\mathrm{P})$-Dy-O$(\mathrm{P})$ angle found in $\mathbf{2}$ compared to $\mathbf{3}$ (Table 1). To obtain the absolute axial limit with these ligands, the equatorial water molecules from 1c-3c have been removed to build models 1d-3d (see Figure 5, S30-31 for beta electron density). For these models, calculations reveals magnetization relaxation via $6^{\text {th }}$

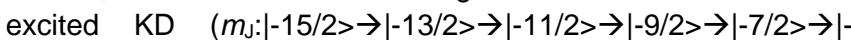
$5 / 2>\rightarrow|-3 / 2>\rightarrow|+3 / 2>\rightarrow|+5 / 2>\rightarrow|+7 / 2>\rightarrow \mid+9 / 2>$

$\rightarrow|+11 / 2>\rightarrow|+13 / 2>\rightarrow \mid+15 / 2>$, Table S35) in $\mathbf{1 d}$ while $\mathbf{2 d}$ and $\mathbf{3 d}$ relaxes via $5^{\text {th }}$ excited KD $\left(m_{\mathrm{J}}:|-15 / 2>\rightarrow|-13 / 2>\rightarrow|-11 / 2>\rightarrow|-\right.$ $9 / 2>\rightarrow|-7 / 2>\rightarrow|-5 / 2>\rightarrow|+5 / 2>\rightarrow|+7 / 2>\rightarrow|+9 / 2>\rightarrow|+11 / 2>$ $\rightarrow|+13 / 2>\rightarrow|+15 / 2>$, Table S36-37). This leads to the $U_{\text {cal }}$ value of $3108.7,3172.8$, and $3188.2 \mathrm{~K}$ for $\mathbf{1 d}, \mathbf{2 d}$, and $\mathbf{3 d}$, respectively.

The water molecules in 1-3 offer significant equatorial ligation which hinders them from achieving a very large blocking barrier. To decrease the equatorial ligand field in $\mathbf{3}$, we have carved out model $\mathbf{3 b}$-acetone where the five equatorial water molecules in $\mathbf{3 b}$ were replaced by acetone (Figure S33 and Appendix S1 for optimized coordinates). The ab initio calculations on 3b-acetone reveal a decrease in the $U_{\text {cal }}$ value to $491.4 \mathrm{~K}$ compared to $\mathbf{3}$ (Table S39). This is due to the loss of planarity in the optimized structure $\mathbf{3 b}$-acetone (Figure S33). Again, the axial
$\mathrm{O}(\mathrm{P})-\mathrm{Dy}-\mathrm{O}(\mathrm{P})$ angle also reduces to $171.48^{\circ}$ compared to $\mathbf{3 b}$ $\left(175.16^{\circ}\right)$. Furthermore, we have also performed calculations on 3b-THF (carved out from 3b with replacing the equatorial $-\mathrm{OH}_{2}$ group by THF, Figure S34, Appendix S2) to reduce the equatorial ligation. But the calculations on these models reveal a decrease in the $U_{\text {cal }}$ value to $427.1 \mathrm{~K}$ due to a decrease of axial $O(P)-D y-$ $\mathrm{O}(\mathrm{P})$ angle (172.22) and loss of equatorial planarity in optimized 3b-THF compared to $\mathbf{3 b}$ (Table S40).

The unsuccessful attempts to enhance the blocking barrier with model $\mathbf{3 b}$-acetone and $\mathbf{3 b}$-THF suggests that the nature of the equatorial donor atom is important compared to its ligand environment in dictating the magnetic anisotropy. Keeping this in mind, we have performed ab initio calculation on model $3-\mathbf{H}_{2} \mathbf{S}$ by replacing the five water molecules of $\mathbf{3}$ with hydrogen sulfide molecules. The optimized structure of $3-\mathrm{H}_{2} \mathrm{~S}$ leads to a decrease in the axial $\mathrm{O}(\mathrm{P})-\mathrm{Dy}-\mathrm{O}(\mathrm{P})$ angle to $168.64^{\circ}$ and at the same time, the equatorial planarity in $\mathbf{3}-\mathbf{H}_{2} \mathbf{S}$ is also lost compared to $\mathbf{3}$ (Figure S35 and Appendix S3). The calculations on $\mathbf{3}-\mathrm{H}_{2} \mathbf{S}$ unveil an increase in the $U_{\text {cal }}$ value to $1325.9 \mathrm{~K}$ compared to 3 with the magnetic relaxation via second excited KD (Table S41). This is due to the reduction of the computed charge of the equatorial sulphur atoms compared to the oxygen atom of the water molecules (Table S42).

\section{Conclusions}

In summary, complexes 1-3 present a series of highperformance pseudo- $D_{5 \mathrm{~h}} \mathrm{Dy}$ (III) $\mathrm{SIMs}$ that are isostructural with the same set of ligand systems in the first coordination sphere. Whereas the high anisotropic barrier mostly results from the strong axial phosphonamide ligands and the higher symmetry around the central Dy(III) ions, the nature of halide ions in the secondary coordination sphere that is hydrogen-bonded to the equatorial coordinated aqua ligand have a profound effect on the relaxation dynamics of the SIMs. The substitution of a larger iodide anion to the smaller strongly hydrogen-bonded chloride anion in the secondary coordination leads to a decrease in the effective energy barrier $\left(U_{\text {eff }}\right)$ and blocking temperature $\left(T_{\mathrm{B}}\right)$ in the order $\mathbf{3}>\mathbf{2}>\mathbf{1}$. Thus, in addition to the first coordination sphere, the secondary coordination sphere can also generate a subsidiary difference in the magnetic properties of SIMs. Ab initio calculations aid the understanding of the effects and role of the secondary coordination sphere in modulating the anisotropy of the $D_{5 \mathrm{~h}}$ systems. In brief, this study presents anion fine-tuning of a fascinating series of air-stable Dy(III) SIMs and highlights the significance of careful selection of secondary coordination sphere anions that can have a subtle effect on the overall performance of molecular magnets. Studies in order to further fine-tune and understand the effect of other factors are currently underway in our laboratory.

\section{Experimental Section}


Materials, instruments, and methods: All the new compounds reported in this study are stable towards air and moisture and hence all the operations were carried out under normal aerobic conditions. Solvents were distilled before use. The phosphonic diamide ligand, ${ }^{t} \mathrm{BuPO}\left(\mathrm{NH}^{\prime} \mathrm{Pr}\right)_{2}$ (L) was synthesized using a previously reported procedure. ${ }^{[11]}$ Fourier transform infrared spectra were obtained on a Perkin Elmer Spectrum One FT-IR spectrometer as $\mathrm{KBr}$ diluted discs. Microanalyses were performed on a ThermoFinnigan (FLASH EA 1112) microanalyzer. The metal content in the samples was measured by inductively coupled plasma atomic emission spectroscopy (ICP-AES). The samples were digested in nitric acid and diluted with distilled water. The magnetic measurements were carried out on a Quantum Design MPMS-XL SQUID magnetometer equipped with a $7 \mathrm{~T}$ magnet in the temperature range $2-300 \mathrm{~K}$ using polycrystalline powder samples. The data were corrected for any background diamagnetic contribution using Pascal's constants. Alternating current (ac) susceptibility measurements were carried out in an oscillating ac field of $3.5 \mathrm{Oe}$ and frequencies ranging from 0.1 to $1500 \mathrm{~Hz}$. Hydrated halides salts of Dy(III) and $Y(\mathrm{III})$ were prepared from the corresponding oxides (Alfa Aesar) using suitable mineral acids.

X-ray crystallography: Suitable single crystals of the complexes, obtained from slow evaporation of the solvent from reaction mixture, were mounted on a Rigaku Saturn 724+ ccd diffractometer for unit cell determination and three-dimensional intensity data collection. Data integration and indexing were carried out using CrystalClear and CrystalStructure. ${ }^{[18]}$ The structures were solved using direct methods (SIR97). ${ }^{[19]}$ Structure refinement and geometrical calculations were carried out using programs in the WinGX[20] module and Olex2 v1.2.[21] The final structure refinement was carried out using full least square methods on $\mathrm{F}^{2}$ using SHELXL-2014. ${ }^{[22]}$ Details of crystal data and structure refinement are reported in Table S1. Crystallographic data of 1 [CCDC 1451546], 2 [CCDC 1451547], 4 [CCDC 1812593] and 5 [CCDC 1812594].

Computational Details: All the ab initio CASSCF/RASSISO/SINGLE_ANISO multireference calculation has been performed on the X-ray crystal structures of $\mathbf{1}, \mathbf{2}$, and $\mathbf{3}$ with MOLCAS 8.2 programme package. ${ }^{[15]}$ The basis sets for our calculations were taken from the ANORCC library implemented in the package. ${ }^{[23]}$ The following basis set was used throughout the calculations: Dy: [Dy.ANO-RCC...8s7p5d3f2g1h.], I: [I.ANO-RCC...6s5p3d1f.], Br: [Br.ANO-RCC...4s4p2d.], Cl: [CI.ANORCC...4s3p1d.], P: [P.ANO-RCC...4s3p.], S: [S.ANO-RCC...5s4p2d1f.], O: [O.ANO-RCC...4s3p2d1f.], N: [N.ANO-RCC...3s2p.], C: [C.ANORCC...3s2p.], H: [H.ANO-RCC...2s.]. The DKH (Douglas-Kroll-Hess) Hamiltonian was used to account the scalar relativistic effect. ${ }^{[15]}$ The disk space was reduced by the Cholesky decomposition technique ${ }^{[24]}$. The active space for our CASSCF calculation includes nine electrons in seven 4 orbitals, i.e., CAS $(9,7)$. Using this active space, we have computed the energies of 21 sextets which are derived from ${ }^{6} H_{15 / 2}$ ground state of Dy(III). In the next step, we have mixed 21 sextets to obtain spin-orbit states. In the final step, we have employed SINGLE ANISO module of MOLCAS to estimate the $g$ tensor, QTM, and blocking barrier. Geometry optimization of models 3- $\mathrm{H}_{2}$ S, 3-acetone, and 3-THF has been carried out with UB3LY functional in Gaussian09 programme package. ${ }^{[25]}$ The Dy(III) ion has been replaced by $Y($ III) during optimization. We have used SDD ECP (electron core potential) for $\mathrm{Y}$, and I, Ahlrichs TZVP basis set for $\mathrm{S}, \mathrm{N}$ and $\mathrm{O}$ and SVP basis set $\mathrm{C}$ and $\mathrm{H}^{[26]}$

General Procedure for the synthesis of $\left\{\left[\mathrm{L}_{2} \mathrm{Ln}\left(\mathrm{H}_{2} \mathrm{O}\right)_{5}\right][\mathrm{X}]_{3} \cdot \mathrm{L}_{2} \cdot n \mathrm{H}_{2} \mathrm{O}\right\}$. To a solution of ${ }^{t} \mathrm{BuPO}\left(\mathrm{NH}^{\mathrm{P}} \mathrm{Pr}\right)_{2}(330 \mathrm{mg}, 1.5 \mathrm{mmol})$ in a solvent mixture of dichloromethane and benzene $(4: 1 \mathrm{v} / \mathrm{v}, 30 \mathrm{~mL})$ was added $\mathrm{LnX} \mathrm{X}_{3} . \mathrm{H}_{2} \mathrm{O}$ $(0.25 \mathrm{mmol})$. The reaction mixture was stirred at $60^{\circ} \mathrm{C}$ for $1 \mathrm{~h}$ and was cooled down to room temperature. The solution was allowed to stand for some time and was then filtered. The clear filtrate obtained was then kept for crystallization at ambient aerobic conditions. Single crystals were obtained by the slow evaporation of the solvent mixture within a week. The crystals were carefully washed with toluene. A few $\mathrm{mL}$ of methanol was necessary for the better dissolution of chloride and bromide salts of Dy(III) and $\mathrm{Y}(\mathrm{III})$

$\left\{\left[\mathrm{L}_{2} \operatorname{Dy}\left(\mathrm{H}_{2} \mathrm{O}\right)_{5}\right][\mathrm{Cl}]_{3} \cdot \mathrm{L}_{2}\right\}$ (1): Yield: $0.160 \mathrm{~g}$ (52\%, based on ligand). Anal. Calcd. for $\mathrm{C}_{40} \mathrm{H}_{110} \mathrm{Cl}_{3} \mathrm{DyN}_{8} \mathrm{O}_{9} \mathrm{P}_{4}$ : C, 38.74; $\mathrm{H}, 8.94 ; \mathrm{N}, 9.04$. Found: C 38.63; H, 8.82; N, 8.74. FT-IR (KBr, cm-1): 3260 (br), 2971 (s), 2873 (w) $1646(\mathrm{w}), 1477(\mathrm{~m}), 1424(\mathrm{~s}), 1399(\mathrm{w}), 1385(\mathrm{w}), 1369(\mathrm{~m}), 1313(\mathrm{w}), 1167$ (s), 1131 (vs), 1098 (vs), 1051 (vs), 1028 (s), 943 (w), 910 (m), 886 (w), $830(\mathrm{w}), 659(\mathrm{~m}), 511(\mathrm{w})$

$\left\{\left[\mathrm{L}_{2} \mathrm{Dy}\left(\mathrm{H}_{2} \mathrm{O}\right)_{5}\right][\mathrm{Br}]_{3} \cdot \mathrm{L}_{2} \cdot \mathrm{H}_{2} \mathrm{O}\right\}$ (2): Yield: $0.150 \mathrm{~g}$ (43\%, based on ligand). M.p: >275 ${ }^{\circ} \mathrm{C}$. Anal. Calcd. for $\mathrm{C}_{40} \mathrm{H}_{112} \mathrm{Br}_{3} \mathrm{DyN}_{8} \mathrm{O}_{10} \mathrm{P}_{4}$ : C, 34.53; H, 8.11; N, 8.05. Found: C, 34.63; H, 8.42; N, 8.14. FT-IR $\left(\mathrm{KBr}, \mathrm{cm}^{-1}\right)$ : $3270(\mathrm{br}), 3178$ (br), 2971 (s), 2935 (w), $2873(w), 1643(w), 1468(\mathrm{~m}), 1422(\mathrm{~s}), 1385(\mathrm{w})$, 1369 (m), 1312 (w), 1168 (s), 1130 (vs), 1097 (vs), 1050 (vs), 1027 (s), $909(\mathrm{~m}), 885(\mathrm{w}), 829(\mathrm{w}), 659(\mathrm{~m}), 603(\mathrm{w}), 509(\mathrm{w})$.

$\left\{\left[\mathrm{L}_{2} \mathrm{Y}\left(\mathrm{H}_{2} \mathrm{O}\right)_{5}\right]\left[\mathrm{Cl}_{3} \cdot \mathrm{L}_{2} \cdot \mathrm{CH}_{2} \mathrm{Cl}_{2}\right\}\right.$ (4): Yield: $0.175 \mathrm{~g}$ (56\%, based on ligand) Anal. Calcd. for $\mathrm{C}_{41} \mathrm{H}_{112} \mathrm{Cl}_{5} \mathrm{~N}_{8} \mathrm{O}_{9} \mathrm{P}_{4} \mathrm{Y}$ : C, 39.35; $\mathrm{H}, 9.02 ; \mathrm{N}, 8.95$. Found: $\mathrm{C}$ 40.1; H, 9.32; N, 9.47. FT-IR (KBr, cm $\left.{ }^{-1}\right): 3262$ (br), 2971 (s), 2871 (w), 1655 (w), 1467 (m), 1478 (s), 1427 (s), 1398 (w), $1385(\mathrm{w}), 1367(\mathrm{~m}), 1320$ (w), 1167 (s), 1132 (vs), 1106 (vs), 1055 (s), 1026 (s), 942 (w), 907 (m), $884(\mathrm{~m}), 830(\mathrm{~m}), 746(\mathrm{~m}), 654(\mathrm{~m}), 513(\mathrm{w}) .{ }^{1} \mathrm{H}$ NMR $\left(\mathrm{CD}_{3} \mathrm{CN}, 400 \mathrm{MHz}\right)$ : $\delta 3.46\left(\mathrm{~m}, 8 \mathrm{H},-\mathrm{CH}\left(\mathrm{CH}_{3}\right)_{2}\right), 1.15-1.21\left(\mathrm{~m}, 84 \mathrm{H},-\mathrm{CH}_{3}\right) .{ }^{13} \mathrm{C} \mathrm{NMR}\left(\mathrm{CD}_{3} \mathrm{CN}\right.$, $100 \mathrm{MHz}): \delta 42.7,32.6,31.4,25.8,25.1,25.0,24.7 .{ }^{31} \mathrm{P} N M R\left(\mathrm{CD}_{3} \mathrm{CN}\right.$, $162 \mathrm{MHz}): \delta 37.2 \mathrm{ppm}$.

$\left\{\left[\mathrm{L}_{2} \mathrm{Y}\left(\mathrm{H}_{2} \mathrm{O}\right)_{5}\right][\mathrm{Br}]_{3} \cdot \mathrm{L}_{2} \cdot \mathrm{H}_{2} \mathrm{O}\right\}$ (5): Yield: $0.160 \mathrm{~g} \mathrm{(49 \% ,} \mathrm{based} \mathrm{on} \mathrm{ligand)}$ Anal. Calcd. for $\mathrm{C}_{40} \mathrm{H}_{112} \mathrm{Br}_{3} \mathrm{~N}_{8} \mathrm{O}_{10} \mathrm{P}_{4} \mathrm{Y}_{1}$ : C, 36.46; $\mathrm{H}, 8.57 ; \mathrm{N}, 8.50$. Found: C, 36.21; H, 8.41; N, 8.82. FT-IR ( $\left.\mathrm{KBr}, \mathrm{cm}^{-1}\right): 3262$ (br), 2968 (s), 2869 (w), 1477 (s), 1464 (s), 1421 (s), 1387 (w), 1365 (m), $1171(\mathrm{~s}), 1132$ (vs), 1108 (vs), $1051(\mathrm{~m}), 1026(\mathrm{~s}), 906(\mathrm{w}), 883(\mathrm{~m}), 831(\mathrm{~m}), 729(\mathrm{w}), 655(\mathrm{w}), 637$ (w), 501 (w). ${ }^{1} \mathrm{H}$ NMR $\left(\mathrm{CD}_{3} \mathrm{CN}, 400 \mathrm{MHz}\right): \delta 3.43\left(\mathrm{br}, 8 \mathrm{H},-\mathrm{CH}\left(\mathrm{CH}_{3}\right)_{2}\right), 3.22$ (br, $\left.10 \mathrm{H}, \mathrm{OH}_{2}\right), 1.20-1.12\left(\mathrm{~m}, 84 \mathrm{H},-\mathrm{CH}_{3}\right) .{ }^{13} \mathrm{C} \mathrm{NMR}\left(\mathrm{CD}_{3} \mathrm{CN}, 100 \mathrm{MHz}\right): \delta$ 42.5, 32.5, 31.3, 25.4, 24.6. ${ }^{31} \mathrm{P}$ NMR $\left(\mathrm{CD}_{3} \mathrm{CN}, 162 \mathrm{MHz}\right): \delta 37.5 \mathrm{ppm}$.

$\left\{\left[\mathrm{L}_{2} \mathrm{Dy}_{0.10} \mathrm{Y}_{0.90}\left(\mathrm{H}_{2} \mathrm{O}\right)_{5}\right][\mathrm{Br}]_{3} \cdot \mathrm{L}_{2} \cdot \mathrm{H}_{2} \mathrm{O}\right\}$ (2@5): $2 @ 5$ was synthesized using a similar method using $1: 9$ molar ratios of the respective Dy(III) and $Y($ III)

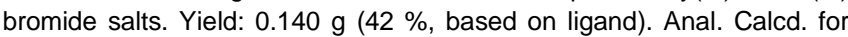
$\mathrm{C}_{40} \mathrm{H}_{112} \mathrm{Br}_{3} \mathrm{Dy}_{0.10} \mathrm{~N}_{8} \mathrm{O}_{10} \mathrm{P}_{4} \mathrm{Y}_{0.9}$ : C, 36.25; $\mathrm{H}, 8.52 ; \mathrm{N}, 8.46$. Found: C, 36.13; H, 8.64; N, 8.74. FT-IR (KBr, cm $\left.{ }^{-1}\right): 3271$ (br), 3181 (br), 2972 (s), 2935 $(w), 2873(w), 1646(w), 1477(m), 1422(s), 1400(w), 1385(w), 1369(m)$, 1312 (w), 1169 (s), 1131 (vs), 1102 (vs), 1050 (s), 1027 (s), 909 (m), 885 (w), $830(w), 659(\mathrm{~m}), 509(\mathrm{w})$.

$\left\{\left[L_{2} \mathrm{Dy}_{0.10} \mathrm{Y}_{0.90}\left(\mathrm{H}_{2} \mathrm{O}\right)_{5}\right][\mathrm{I}]_{3} \cdot \mathrm{L}_{2} \cdot \mathrm{H}_{2} \mathrm{O}\right\}(3 @ 6)$ : 3@6 was synthesized using a similar method using $1: 9$ molar ratios of the respective Dy(III) and $Y($ III) iodide salts. Yield: $0.165 \mathrm{~g}$ (45\%, based on ligand). Anal. Calcd. for $\mathrm{C}_{40} \mathrm{H}_{112} \mathrm{Dy}_{0.10} \mathrm{l}_{3} \mathrm{~N}_{8} \mathrm{O}_{10} \mathrm{P}_{4} \mathrm{Y}_{0.9}: \mathrm{C}, 32.77 ; \mathrm{H}, 7.70 ; \mathrm{N}, 7.64$. Found: C, 32.56; $\mathrm{H}$, 7.61; N, 7.78. FT-IR (KBr, cm $\left.{ }^{-1}\right): 3286(\mathrm{br}), 2969$ (vs), 2909 (m), $2872(\mathrm{w})$, $1469(\mathrm{~m}), 1420(\mathrm{~s}), 1399(\mathrm{w}), 1386(\mathrm{w}), 1368(\mathrm{~m}), 1311(\mathrm{w}), 1168(\mathrm{~s}), 1131$ (vs), 1105 (vs), 1049 (s), 1024 (s), 942 (w), 906 (m), 885 (w), 829 (w), 727 (w), $655(\mathrm{~m}), 544(\mathrm{w}), 512(\mathrm{w})$.

\section{Acknowledgments}

This work was supported by SERB and DST Nanomission, New Delhi, and DAE (BRNS), Mumbai. RM thanks BRNS for the award of DAE-SRC Outstanding Investigator Award and SERB/DST for 
a J. C. Bose Fellowship. SKG thanks UGC and IRCC, IIT Bombay for a research fellowship. SD thanks to UGC for SRF fellowship. SD thanks to CRAY space time computing facility of IIT Bombay. GR would like to thank DST/SERB for funding (CRG/2018/00430; DST/CSA-03/2018-10; SB/SJF/2019-20/12; SPR/2019/001145).

Keywords: Dysprosium(III) • Single-ion Magnet • Anisotropy • Blocking temperature $\cdot D_{5 \mathrm{~h}} \cdot$ Axiality 
[1] a) D. Gatteschi, R. Sessoli, J. Villain, Molecular nanomagnets, Oxford University Press, Oxford, 2011; b) D. N. Woodruff, R. E. P. Winpenny, R A. Layfield, Chem. Rev. 2013, 113, 5110-5148; c) J. Tang, P. Zhang, Lanthanide Single Molecule Magnets, Springer Berlin Heidelberg, 2015; d) S. K. Gupta, R. Murugavel, Chem. Commun. 2018, 54, 3685-3696.

[2] a) M. Mannini, F. Pineider, P. Sainctavit, C. Danieli, E. Otero, C Sciancalepore, A. M. Talarico, M.-A. Arrio, A. Cornia, D. Gatteschi, R Sessoli, Nature Mater. 2009, 8, 194-197; b) R. Sessoli, Nature 2017, 548, 400-401; c) R. Marin, G. Brunet, M. Murugesu, Angew. Chem. Int. Ed. n/a.

[3] a) M. Urdampilleta, S. Klyatskaya, J. P. Cleuziou, M. Ruben, W. Wernsdorfer, Nature Mater 2011, 10, 502-506; b) L. Bogani, W. Wernsdorfer, Nat. Mater. 2008, 7, 179; c) M. Mannini, F. Pineider, C. Danieli, F. Totti, L. Sorace, P. Sainctavit, M. A. Arrio, E. Otero, L. Joly, J. C. Cezar, A. Cornia, R. Sessoli, Nature 2010, 468, 417-421; d) D. Aravena, E. Ruiz, Dalton Trans. 2020, 49, 9916-9928.

[4] a) R. Sessoli, D. Gatteschi, A. Caneschi, M. A. Novak, Nature 1993, 365 141-143; b) A. Caneschi, D. Gatteschi, R. Sessoli, A. L. Barra, L. C Brunel, M. Guillot, J. Am. Chem. Soc. 1991, 113, 5873-5874.

[5] N. Ishikawa, M. Sugita, T. Ishikawa, S.-y. Koshihara, Y. Kaizu, J. Am. Chem. Soc. 2003, 125, 8694-8695.

[6] a) J. D. Rinehart, J. R. Long, Chem. Sci. 2011, 2, 2078-2085; b) A. J. Brown, D. Pinkowicz, M. R. Saber, K. R. Dunbar, Angew. Chem. Int. Ed 2015, 54, 5864-5868; c) C. A. Gould, K. R. McClain, J. M. Yu, T. J. Groshens, F. Furche, B. G. Harvey, J. R. Long, J. Am. Chem. Soc. 2019 141, 12967-12973; d) Y.-S. Ding, N. F. Chilton, R. E P Winpenny, Y.-Z Zheng, Angew. Chem. Int. Ed. 2016, 55, 16071-16074; e) R. J. Blagg, L. Ungur, F. Tuna, J. Speak, P. Comar, D. Collison, W. Wernsdorfer, E. J. L. McInnes, L. F. Chibotaru, R. E. P. Winpenny, Nature Chem. 2013, 5 673-678; f) S. K. Gupta, T. Rajeshkumar, G. Rajaraman, R. Murugavel, Chem. Sci. 2016, 7, 5181-5191; g) L. Sorace, C. Benelli, D. Gatteschi, Chem. Soc. Rev. 2011, 40, 3092-3104.

[7] a) J. D. Rinehart, M. Fang, W. J. Evans, J. R. Long, Nature Chem. 2011 3, 538-542; b) S. K. Langley, D. P. Wielechowski, B. Moubaraki, K. S Murray, Chem. Commun. 2016, 52, 10976-10979; c) S. K. Langley, D. P. Wielechowski, V. Vieru, N. F. Chilton, B. Moubaraki, L. F. Chibotaru, K. S. Murray, Chem. Sci. 2014, 5, 3246-3256; d) J. D. Rinehart, M. Fang W. J. Evans, J. R. Long, J. Am. Chem. Soc. 2011, 133, 14236-14239.

[8] a) S. K. Gupta, T. Rajeshkumar, G. Rajaraman, R. Murugavel, Dalton Trans. 2018, 47, 357-366; b) F.-S. Guo, B. M. Day, Y.-C. Chen, M.-L. Tong, A. Mansikkamäki, R. A. Layfield, Angew. Chem. Int. Ed. 2017, 56, 11445-11449; c) C. A. P. Goodwin, F. Ortu, D. Reta, N. F. Chilton, D. P. Mills, Nature 2017, 548, 439-442; d) F.-S. Guo, B. M. Day, Y.-C. Chen, M.-L. Tong, A. Mansikkamäki, R. A. Layfield, Science 2018, 362, 1400 1403; e) S. Demir, J. M. Zadrozny, M. Nippe, J. R. Long, J. Am. Chem. Soc. 2012, 134, 18546-18549; f) Y.-N. Guo, G.-F. Xu, W. Wernsdorfer L. Ungur, Y. Guo, J. Tang, H.-J. Zhang, L. F. Chibotaru, A. K. Powell, J. Am. Chem. Soc. 2011, 133, 11948-11951.

[9] a) K.-X. Yu, J. G. C. Kragskow, Y.-S. Ding, Y.-Q. Zhai, D. Reta, N. F. Chilton, Y.-Z. Zheng, Chem 2020, 6, 1777-1793; b) S. K. Gupta, T. Rajeshkumar, G. Rajaraman, R. Murugavel, Chem. Commun. 2016, 52 7168-7171; c) Y.-C. Chen, J.-L. Liu, L. Ungur, J. Liu, Q.-W. Li, L.-F. Wang Z.-P. Ni, L. F. Chibotaru, X.-M. Chen, M.-L. Tong, J. Am. Chem. Soc. 2016, 138, 2829-2837; d) A. B. Canaj, S. Dey, E. R. Martí, C. Wilson, G Rajaraman, M. Murrie, Angew. Chem. Int. Ed. 2019, 58, 14146-14151 e) Z.-H. Li, Y.-Q. Zhai, W.-P. Chen, Y.-S. Ding, Y.-Z. Zheng, Chem. Eur J. 2019, 25, 16219-16224; f) X.-L. Ding, Y.-Q. Zhai, T. Han, W.-P. Chen, Y.-S. Ding, Y.-Z. Zheng, Chem. Eur. J., n/a; g) M. J. Giansiracusa, A. K Kostopoulos, D. Collison, R. E. P. Winpenny, N. F. Chilton, Chem Commun. 2019, 55, 7025-7028; h) Z. Zhu, C. Zhao, T. Feng, X. Liu, X Ying, X.-L. Li, Y.-Q. Zhang, J. Tang, J. Am. Chem. Soc. 2021, 143, 10077-10082.

[10] a) V. S. Parmar, F. Ortu, X. Ma, N. F. Chilton, R. Clérac, D. P. Mills, R E. P. Winpenny, Chem. Eur. J. 2020, 26, 7774-7778; b) S. Vaidya, S. K. Singh, P. Shukla, K. Ansari, G. Rajaraman, M. Shanmugam, Chem. Eur. J. 2017, 23, 9546-9559.

[11] R. Murugavel, R. Pothiraja, New J. Chem. 2003, 27, 968-974.
[12] M. Llunell, D. Casanova, J. Cirera, J. Bofill, P. Alemany, S. Alvarez, SHAPE (version 2.1), Barcelona, 2013.

[13] a) S. K Singh, T. Gupta G. Rajaraman, Inorg Chem 2014, 53, 10835 10845 ; b) N. F. Chilton, C. A. P. Goodwin, D. P. Mills, R. E. P. Winpenny Chem. Commun. 2015, 51, 101-103; c) N. F. Chilton, Inorg. Chem. 2015, 54, 2097-2099.

[14] E. Lucaccini, L. Sorace, M. Perfetti, J.-P. Costes, R. Sessoli, Chem Commun. 2014, 50, 1648-1651.

[15] F. Aquilante, J. Autschbach, R. K. Carlson, L. F. Chibotaru, M. G. Delcey L. De Vico, I. Fdez. Galván, N. Ferré, L. M. Frutos, L. Gagliardi, M. Garavelli, A. Giussani, C. E. Hoyer, G. Li Manni, H. Lischka, D. Ma, P. Å Malmqvist, T. Müller, A. Nenov, M. Olivucci, T. B. Pedersen, D. Peng, F. Plasser, B. Pritchard, M. Reiher, I. Rivalta, I. Schapiro, J. Segarra-Martí, M. Stenrup, D. G. Truhlar, L. Ungur, A. Valentini, S. Vancoillie, V. Veryazov, V. P. Vysotskiy, O. Weingart, F. Zapata, R. Lindh, J. Comput Chem. 2016, 37, 506-541.

[16] a) M. S. Norre, C. Gao, S. Dey, S. K. Gupta, A. Borah, R. Murugavel, G. Rajaraman, J. Overgaard, Inorg. Chem. 2020, 59, 717-729; b) P. Kalita N. Ahmed, A. K. Bar, S. Dey, A. Jana, G. Rajaraman, J.-P. Sutter, V. Chandrasekhar, Inorg. Chem. 2020, 59, 6603-6612; c) A. B. Canaj, S. Dey, C. Wilson, O. Céspedes, G. Rajaraman, M. Murrie, Chem. Commun. 2020, 56, 12037-12040; d) A. B. Canaj, S. Dey, O. Céspedes, C. Wilson, G. Rajaraman, M. Murrie, Chem. Commun. 2020, 56, 1533-1536; e) I. F. Díaz-Ortega, J. M. Herrera, S. Dey, H. Nojiri, G. Rajaraman, E. Colacio Inorganic Chemistry Frontiers 2020, 7, 689-699; f) A. Borah, S. Dey, S. K. Gupta, M. G. Walawalkar, G. Rajaraman, R. Murugavel, Chem. Commun. 2020, 56, 11879-11882; g) S. Dey, G. Rajaraman, Dalton Trans. 2020, 49, 14781-14785; h) A. B. Canaj, M. K. Singh, C. Wilson G. Rajaraman, M. Murrie, Chem. Commun. 2018, 54, 8273-8276; i) A. B Canaj, M. K. Singh, E. Regincós Marti, M. Damjanović, C. Wilson, O. Céspedes, W. Wernsdorfer, G. Rajaraman, M. Murrie, Chem. Commun. 2019, 55, 5950-5953.

[17] D. Aravena, E. Ruiz, Inorg. Chem. 2013, 52, 13770-13778.

[18] CrystalClear, Version-SM Expert 2.0 r4, 2009 and CrystalStructure, Version 4.0, Rigaku, 2010, Rigaku Americas and Rigaku, The Woodlands, Texas, USA and Rigaku Corporation, Tokyo, Japan.

[19] A. Altomare, M. C. Burla, M. Camalli, G. L. Cascarano, C. Giacovazzo A. Guagliardi, A. G. G. Moliterni, G. Polidori, R. Spagna, J. Appl. Crystallogr. 1999, 32, 115-119.

[20] L. Farrugia, J. Appl. Crystallogr. 2012, 45, 849-854.

[21] O. V. Dolomanov, L. J. Bourhis, R. J. Gildea, J. A. K. Howard, H. Puschmann, J. Appl. Crystallogr. 2009, 42, 339-341.

[22] G. Sheldrick, Acta Cryst. 2015, C71, 3-8.

[23] B. O. Roos, R. Lindh, P.-A. Malmqvist, V. Veryazov, P.-O. Widmark, A C. Borin, J. Phys. Chem. A 2008, 112, 11431-11435.

[24] V. Veryazov, P.-O. Widmark, L. Serrano-Andrés, R. Lindh, B. O. Roos Int. J. Quantum Chem 2004, 100, 626-635.

[25] a) A. D. Becke, J. Chem. Phys. 1993 , 98, 5648-5652; b) M. J. Frisch, G. W. Trucks, H. B. Schlegel, G. E. Scuseria, M. A. Robb, J. R. Cheeseman G. Scalmani, V. Barone, B. Mennucci, G. A. Petersson, H. Nakatsuji, M Caricato, X. Li, H. P. Hratchian, A. F. Izmaylov, J. Bloino, G. Zheng, J. L. Sonnenberg, M. Hada, M. Ehara, K. Toyota, R. Fukuda, J. Hasegawa, M. Ishida, T. Nakajima, Y. Honda, O. Kitao, H. Nakai, T. Vreven, J. A. Montgomery Jr., J. E. Peralta, F. Ogliaro, M. J. Bearpark, J. Heyd, E. N Brothers, K. N. Kudin, V. N. Staroverov, R. Kobayashi, J. Normand, K. Raghavachari, A. P. Rendell, J. C. Burant, S. S. lyengar, J. Tomasi, M. Cossi, N. Rega, N. J. Millam, M. Klene, J. E. Knox, J. B. Cross, V. Bakken, C. Adamo, J. Jaramillo, R. Gomperts, R. E. Stratmann, O. Yazyev, A. J. Austin, R. Cammi, C. Pomelli, J. W. Ochterski, R. L. Martin, K. Morokuma, V. G. Zakrzewski, G. A. Voth, P. Salvador, J. J. Dannenberg, S. Dapprich, A. D. Daniels, Ö. Farkas, J. B. Foresman, J. V. Ortiz, J. Cioslowski, D. J. Fox, Gaussian, Inc., Wallingford, CT, USA, 2013.

[26] a) A. Schäfer, C. Huber, R. Ahlrichs, J. Chem. Phys. 1994, 100, 5829 5835 ; b) T. Dunning, P. Hay, pp. in Modern Theoretical Chemistry, Vol. 3, Plenum Press, New York 1977. 


\section{Entry for the Table of Contents}

\section{FULL PAPER}

Bigger the better!! The change of hydrogen-bonded halide anions in the secondary coordination sphere of a pseudo- $D_{5 \mathrm{~h}} \mathrm{Dy}$ (III) single-ion magnet shows a subtle alteration in the magnetic properties. The $U_{\text {eff }}$ and $T_{\mathrm{B}}$ decrease in the order $\mathrm{I}>\mathrm{Br}>\mathrm{Cl}$ through change of anions in the secondary coordination sphere from larger iodide to smaller chloride ions.

\section{Secondary Coordination}

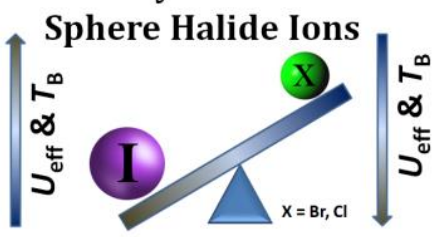

Dy(III) Single-Ion Magnets
Sandeep K. Gupta, Sourav Dey, Thayalan Rajeshkumar, Gopalan Rajaraman* and Ramaswamy Murugavel $^{*}$

Page No. - Page No. Anion-tuning of Dy(III) Single-lon Magnets: Effect of $\mathrm{H}$-bonded Secondary Coordination Sphere Halide lons 